\title{
Effect of readmissions on increasing hospital admissions for asthma in children
}

\author{
A Senthilselvan
}

\begin{abstract}
Background - Previous studies have reported increases in the number of hospital admissions for asthma in children. The aim of the present study was to examine the effect of readmissions on these increased hospital admissions and to investigate gender differences in asthma readmissions.
\end{abstract}

Methods - The Provincial Government of Saskatchewan provides universal health care to its residents. Hospital admissions data for asthma were obtained from the Saskatchewan Health Department for all 134 hospitals in the province between 1980 and 1989. Age-specific and sex-specific hospital admission rates for asthma were calculated for each calendar year using first admissions and all admissions. The ratio between the number of readmissions and all admissions in a year was defined as the readmission rate for that year.

Results - Although rates based on all admissions for asthma were greater than rates based on first admissions, trends and sex differences were similar for the two rates. Despite the higher hospital admission rates for boys aged 10-14 years, girls in this age group had higher readmission rates for asthma from 1981 to 1989 (odds ratio (OR) 1.6 for girls; 95\% confidence intervals (CI) $1 \cdot 3$ to $1 \cdot 9$ ). Similar increases were observed in readmission rates for asthma among children aged 5-9 years from 1985 to 1989 (OR $1 \cdot 3$ for girls; $95 \%$ CI $1 \cdot 1$ to $1 \cdot 5$ ).

Conclusions - Readmissions for asthma do not seem to explain the increasing trend in hospital admissions for asthma in children. In children aged 10-14 years girls had higher hospital readmission rates for asthma than boys, and further studies are required to find factors related to the increased readmissions among girls in this age group.

(Thorax 1995;50:934-936)

Keywords: asthma, readmissions, sex.

Several studies have used hospital discharge data to investigate changes in asthma morbidity. ${ }^{1-8}$ However, authors were not able to distinguish between first admissions and re- admissions, and therefore were unable to determine whether the apparent increases in hospital admissions were due to an increase in the numbers of readmissions or an increase in asthma prevalence. Anderson investigated readmissions for asthma among children and concluded that part of the increased number of admissions for asthma in children under 15 years of age might be due to readmissions. ${ }^{9}$ However, that study was based on data from six hospitals and a subject admitted under a different case number was considered a first admission. ${ }^{9}$ In a study investigating trends in asthma admissions among members of a private health maintenance organisation, readmissions for asthma did not explain the increases in hospital admission rates in boys aged 0-14 years. ${ }^{10}$ Female sex, young age, number of previous admissions, and inpatient intravenous treatment were found to be significant factors associated with readmissions for asthma in a hospital based three year follow up study of children in Auckland, New Zealand. ${ }^{11}$

In the current study trends in hospital admission rates based on first admissions were compared with the rates for all admissions for children under 14 years of age in the province of Saskatchewan between 1980 and 1989. Gender differences in readmission rates were also examined in the age groups $0-4,5-9$, and 10-14 years.

\section{Methods}

The population of Saskatchewan is about 1.01 million and comprises persons of Caucasian, Native Indian, and other origins. ${ }^{12}$ The Government of Saskatchewan provides universal health care insurance to its residents. Discharge data for all respiratory diseases (International Classification of Diseases Ninth Revision (ICD-9) 460-519) were obtained from the Urban Hospitals Branch of the Saskatchewan Health Department for all 134 hospitals in the province. We have previously studied trends, racial, and regional differences in hospital admissions for asthma in Saskatchewan. ${ }^{1314}$ Subjects were assigned unique identification numbers during the study period to distinguish between first and subsequent admissions for asthma.

Age-specific and sex-specific hospital admission rates for asthma were obtained for the Saskatchewan population by dividing the 


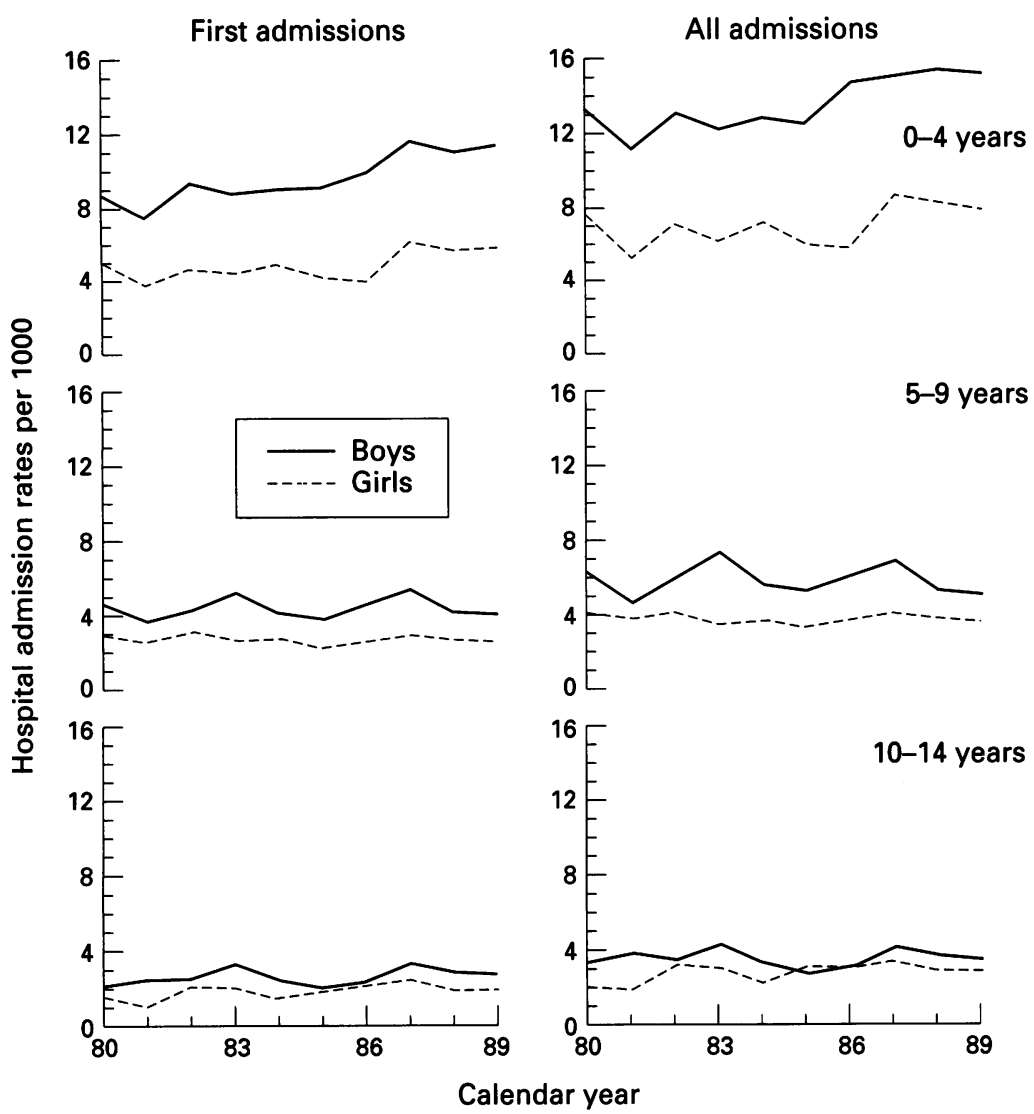

Figure 1 Hospital admission rates for asthma for first and all admissions according to age, sex, and calendar year for children under 14 years of age in Saskatchewan.

number of hospital admissions for asthma (ICD-9 493) by the number of residents in Saskatchewan for the years 1980-9 obtained from the health insurance registration file. The readmission rate for a calendar year was obtained by dividing the number of readmissions by the total number of admissions in that calendar year.

Simple linear regression analysis was used to test the trends in hospital admission rates for asthma. Gender differences in readmission rates were expressed as odds ratios with $95 \%$ confidence intervals. Odds ratios were obtained by fitting independent logistic regression models in the three age groups $0-4,5-9$, and 10-14 years.

\section{Results}

Rates based on first and all hospital admissions for asthma are shown in fig 1 for boys and girls in the study age groups. These rates were
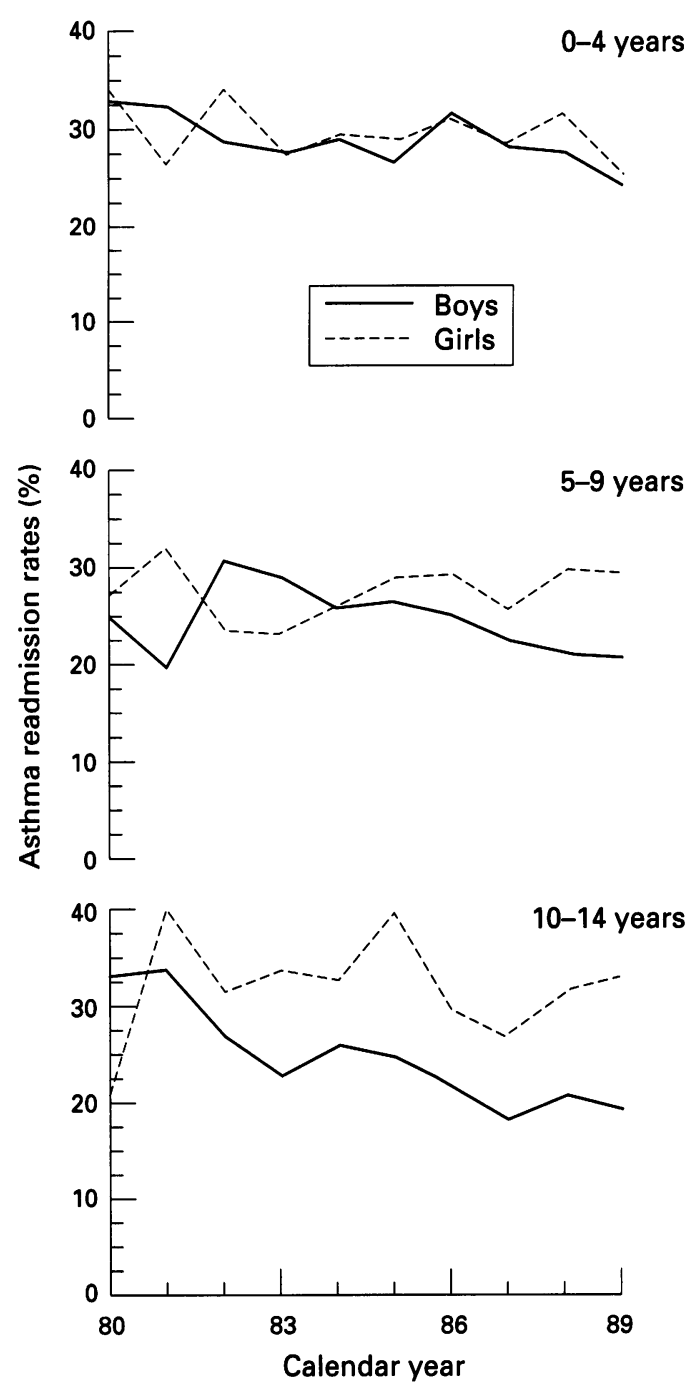

Figure 2 Readmission rates (\%) for asthma according to age, sex, and calendar year for children under 14 years of age in Saskatchewan.

greater for boys than for girls in all three age groups. In the 0-4 year group hospital admission rates for asthma for both first and all admissions increased significantly between 1980 and 1989 for both boys and girls. No significant increases were observed in hospital admission rates for asthma in the other age groups.

Asthma readmission rates are given for all the age groups in the table. A decline was observed in asthma readmission rates from 1980 to 1989 in children under four years of age. In children aged 5-9 years asthma

Number of hospital readmissions, all admissions, and readmission rates* for asthma by age and calendar year for children under 14 years of age in Saskatchewan, 1980-9

\begin{tabular}{|c|c|c|c|c|c|c|c|c|c|}
\hline \multirow[t]{2}{*}{ Year } & \multicolumn{3}{|l|}{$0-4$ years } & \multicolumn{3}{|l|}{ 5-9 years } & \multicolumn{3}{|l|}{$10-14$ years } \\
\hline & Readmissions & $\begin{array}{l}\text { All } \\
\text { admissions }\end{array}$ & $\begin{array}{l}\text { Readmission } \\
\text { rates (\%) }\end{array}$ & Readmissions & $\begin{array}{l}\text { All } \\
\text { admissions }\end{array}$ & $\begin{array}{l}\text { Readmission } \\
\text { rates }(\%)\end{array}$ & Readmissions & $\begin{array}{l}\text { All } \\
\text { admissions }\end{array}$ & $\begin{array}{l}\text { Readmission } \\
\text { rates }(\%)\end{array}$ \\
\hline $\begin{array}{l}1980 \\
1981 \\
1982 \\
1983 \\
1984 \\
1985 \\
1986 \\
1987 \\
1988 \\
1989\end{array}$ & $\begin{array}{l}287 \\
208 \\
263 \\
219 \\
256 \\
226 \\
285 \\
312 \\
293 \\
239\end{array}$ & $\begin{array}{r}858 \\
682 \\
859 \\
793 \\
877 \\
823 \\
907 \\
1099 \\
1016 \\
971\end{array}$ & $\begin{array}{l}33 \cdot 4 \\
30 \cdot 5 \\
30 \cdot 6 \\
27 \cdot 6 \\
29 \cdot 2 \\
27 \cdot 5 \\
31 \cdot 4 \\
28 \cdot 4 \\
28 \cdot 8 \\
24 \cdot 6\end{array}$ & $\begin{array}{r}106 \\
84 \\
115 \\
120 \\
100 \\
99 \\
113 \\
111 \\
96 \\
90\end{array}$ & $\begin{array}{l}411 \\
338 \\
414 \\
443 \\
388 \\
361 \\
425 \\
470 \\
391 \\
373\end{array}$ & $\begin{array}{l}25 \cdot 8 \\
24 \cdot 9 \\
27 \cdot 8 \\
27 \cdot 1 \\
25 \cdot 8 \\
27 \cdot 4 \\
26 \cdot 6 \\
23 \cdot 6 \\
24 \cdot 6 \\
24 \cdot 1\end{array}$ & $\begin{array}{l}61 \\
83 \\
77 \\
81 \\
64 \\
75 \\
62 \\
65 \\
66 \\
64\end{array}$ & $\begin{array}{l}215 \\
233 \\
267 \\
300 \\
224 \\
233 \\
243 \\
295 \\
261 \\
254\end{array}$ & $\begin{array}{l}28 \cdot 4 \\
35 \cdot 6 \\
28 \cdot 8 \\
27 \cdot 0 \\
28 \cdot 6 \\
32 \cdot 2 \\
25 \cdot 5 \\
22 \cdot 0 \\
25 \cdot 3 \\
25 \cdot 2\end{array}$ \\
\hline
\end{tabular}

* Asthma readmission rates were calculated by dividing the number of readmissions by all admissions and given as percentages. 


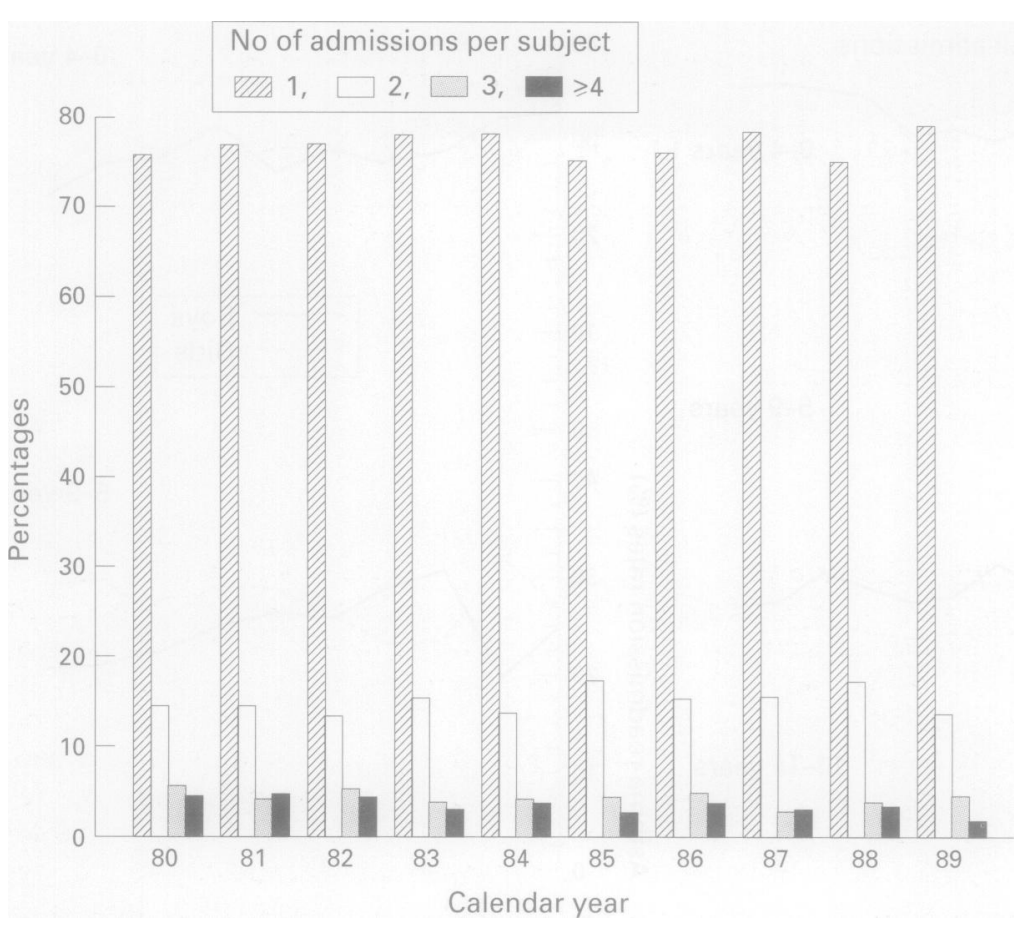

Figure 3 Number of admissions for asthma per subject according to calendar year for children under 14 years of age in Saskatchewan.

readmission rates were fairly stable during the study period, while in children aged 10-14 years a small decrease occurred in asthma readmission rates.

The readmission rates for asthma of boys and girls of all age groups are illustrated in fig 2 . In children under four years no significant differences were observed in readmission rates between boys and girls. Despite the higher rates of hospital admission for asthma among boys in the age group 10-14 years, girls had higher readmission rates than boys from 1981 onwards. In this age group the risk for readmission for asthma was significantly greater for girls than for boys during the period 1982-9 (odds ratio (OR) 1.6 for girls; $95 \%$ confidence intervals (CI) 1.3 to 1.9 ; $p<0.001$ ). Asthma readmission rates were higher in girls in the 5-9 age group only in the period 1985-9 (OR 1.3 for girls; CI 1.1 to $1.5 ; p<0.05$ ).

The number of admissions for asthma per subject for each calendar year for children under 14 years of age is given in fig 3. Most of the children (70-80\%) had only one admission in a calendar year. On average, $10-20 \%$ of the children had two admissions per year, 3-5\% had three, and $3-4 \%$ had four or more admissions per year.

\section{Discussion}

Previous studies have reported that apparent increases in asthma morbidity occur mainly in children aged four years and under. ${ }^{125-1013}$ The present study also found significant increases in hospital admissions for asthma only among children aged four years and under. Since increases in the number of hospital admissions were observed for both first and all admissions, these increases appear to be independent of readmissions.

Small decreases were seen in readmission rates for asthma between 1980 and 1989. This was unexpected as the introduction of new asthma medications and increased parental knowledge of management of asthma might have caused the readmissions to decrease. A decrease was observed from 1981 to 1987 in readmission rates among children under 14 years of age who were covered by a health maintenance organisation, suggesting that parents may be from a higher socioeconomic class. ${ }^{10}$ The decreases in readmission rates in children may therefore be related to better management of asthma at home compared with the general population of Saskatchewan.

We found that hospital admission rates were higher among boys and similar trends have also been reported for other populations. ${ }^{15}$ Gender differences did not depend on whether the rates were calculated using first admissions or all admissions.

An important finding in our study was that readmission rates were higher among girls than among boys aged 10-14 years for each year from 1981 to 1989 . Similar differences were observed in the 5-9 age group in the latter part of the study. One explanation for the finding in children aged 10-14 years is that, while asthma may be more prevalent among boys than girls as judged by hospital admission rates, its severity may be greater for girls than boys in this age group. The reasons for these differences are not known.

In conclusion, readmissions for asthma do not explain the increases in hospital admissions for asthma in young children. Further studies are required to determine the factors related to the increased readmission rate for asthma in girls of 10-14 years.

1 Gergen PJ, Weiss KB. Changing patterns of asthma hospitalization among children 1979 to 1987. $\mathcal{F} A M A 1990$; 264:168-92.

2 Carr W, Zeitel L, Weiss $\mathrm{K}$. Variations in asthma hospitalizations and deaths in New York City. Am $\mathcal{f}$ Public Health 1992;82:59-65.

3 Wilkins K, Mao Y. Trends in rates of admission to hospital and death from asthma among children and young adults in Canada

4 Mitchell EA. International trends in hospital admission rates for asthma. Arch Dis Child 1985;60:295-300.

5 Anderson HR. Increase in hospitalization for childhood asthma: trends in referral, severity, and readmissions from 1970 to 1985 in a health region of the United Kingdom. Thorax 1989;44:614-9.

6 Mitchell EA, Jackson RT. Recent trends in asthma mortality, morbidity and management in New Zealand. $\mathcal{f}$ Asthma 1989;26:349-54.

7 Wever-Hess J, Wever AMJ, Yntema JL. Mortality and morbidity from respiratory diseases in childhood in the Nethbidity from respiratory diseases in childhood in the

8 Carman PG, Landau LI. Increased pediatric admissions with asthma in Western Australia - a problem of diagnosis? Med f Aust 1990;152:23-6.

9 Anderson HR. Increase in hospitalisation for childhood asthma. Arch Dis Child 1978;53:295-300.

10 Vollmer WM, Buist AS, Osborne ML. Twenty year trends in hospital discharges for asthma among members of a health maintenance organization. F Clin Epidemiol 1992; 45:999-1006.

11 Mitchell EA, Bland JM, Thompson JMD. Risk factors for readmission to hospital for asthma in childhood. Thorax 1994;49:33-6.

12 Census: Saskatchewan. Profiles, 1986 Census. Ottawa: Statistics Canada, 1988, Cat. No. 94-116.

13 Senthilselvan A. Trends and rural-urban differences in asthma hospitalizations in Saskatchewan 1970-1989. Can Respir ₹ 1995;1:229-34.

14 Senthilselvan A, Habbick BF. Increased asthma hospitalizations among Registered Indian children and adults pitalizations among Registered Indian children and adults
in Saskatchewan, 1970-1989. F Clin Epidemiol 1995 (in in Saskatc.

15 Skobeloff EM, Spivey WH, St. Clair SS, Schoffstall JM. The influence of age and sex on asthma admissions. $¥ A M A$ 1992;268:3437-40. 